\title{
Impact of Portfolio Strategies on Portfolio Performance and Risk
}

\author{
Zunera Shaukat $^{1} \&$ Ahmad Shahzad ${ }^{1}$ \\ ${ }^{1}$ Lahore School of Accountancy \& Finance, The University of Lahore, Pakistan. \\ Correspondence: Zunera Shaukat, Lahore School of Accountancy \& Finance, The University of Lahore, Pakistan.
}

Received: December 18, 2018

Accepted: January 11, 2019

Online Published: January 21, 2019

doi:10.5430/ijba.v10n1p73

URL: https://doi.org/10.5430/ijba.v10n1p73

\begin{abstract}
The Portfolio strategies are the effective investment tools pertaining to active and passive investment approaches. This signifies the investor's inclination of buying and selling the risky and risk-free assets. The research includes four strategies namely buy and hold strategy, dynamic asset allocation, strategic asset allocation and tactical asset allocation along with their dimensions. Strategies based hypothetical portfolios are generated on the basis of 14 years' stock prices (2005-2017). The annually and monthly risk-adjusted return ratios; Sharpe ratio, Treynor's measure, CAPM and Jenson Alpha are calculated individually. Simulated annualized portfolios generate significant result with Sharpe and treynor measure. Alpha return is generated with buy and hold if based on growth in stock prices. For empirical result, One-way analysis of variance (ANOVA) is used for studying the relationship between the strategies. Post hoc Tukey's test is applied to find the difference between the strategies. The ANOVA and Tukey's post hoc test for monthly portfolios gives significant results with three measure Sharpe ratio, CAPM and Jenson Alpha. No empirical significant result is measured on the basis of treynor measure.
\end{abstract}

Keywords: portfolio strategies, buy and hold, dynamic asset allocation, strategic asset allocation, tactical asset allocation, risk-adjusted return, ANOVA, Tukey's post hoc test

\section{Introduction}

\subsection{Portfolio Investment Inpacts on Performance and Risk}

Developing the portfolio is a financial art. The art that enables the investors to manage the funds or more precisely means managing the scarce funds. Investors have the options to select and invest according to the conditions of market. Mattei and Mattei (2016), defined that strategies of asset allocation are devised to help investor in diversifying their portfolio and for lessening the risk. In the rapidly moving financial markets, domestic and global, the seasoned experts could make the best choices out of the various available investment options, suiting to their financial goals.

Four Types of portfolio strategies are considered namely; buy and hold Strategy, dynamic asset allocation or constant mix strategy, strategic asset allocation and tactical asset allocation.

Ling, Yat, and binti Muhamad (2014) described buy and hold as passive conservative investment strategy, in which an investor holds the stocks for a longer period of time. Buy and Hold Strategy is based on the ratio of 40/60 between the bonds and stocks respectively. Mattei and Mattei (2016) defined that among all the most significant division of portfolio is to invest $60 \%$ in stocks and $40 \%$ in bonds. In this research, the significant ratio $60 / 40$ is used for generating the portfolio.

The dynamic asset allocation based on the strategy of shifting to debt when equity market is rising and towards equity, if equity market falls. Frequency of rebalancing is not rigid. Perold and Sharpe (1995a) described that dynamic strategy will maintain a constant proportion of wealth to the value of stocks and stocks will be hold at all wealth levels. Price to earnings ratio is the tool for defining the shift between the ratio of stocks and bonds. In this research, the dynamic asset allocation is based price to earnings ratio of stock. The stock with more price to earnings ratio will get more weightage in portfolio.

Strategic asset allocation is another strategy which is based on the long term investment goals with less correlation among the stocks. Anson (2004), described that under the normal market conditions strategic asset allocation is defined to meet the long term investment goals of the organization. It lasts for up to ten years for full stock market cycle. This research based the strategic asset allocation lower correlation among stocks. 
The fourth Strategy, tactical asset allocation is based on the analyzing the trends and inefficiencies in the market. Anson (2004) described that tactical asset allocation attempts to beat the market and is chosen to get the benefit from the market in case the market is out of order. This research worked on price to book value anomaly to capitalize the stock returns. This anomaly says that if the company has lower price to book value ratio in the last quarter of the year, the stock is likely to outperform the next year.

The First ratio of measuring the risk-adjusted return is the Sharpe ratio presented by William F. Sharpe. The ratio considered the standard deviation of the portfolio instead of considering the systematic risk, as measured by Beta. The higher the Sharpe ratio, the better the portfolio performance. Jobson \& Korkie, (1981) tested the hypothesis using the Sharpe ratio. Sharpe (1994), discussed the Sharpe ratio with various aspects of its measurements.

The measurement techniques used are Treynor measure or reward to volatility measure was presented by the Jack L. Treynor measures the portfolio performance on the risk-adjusted basis. It also calculated the investment's performance per unit of the risk. The higher the Treynors measure, the better the portfolio. Jobson \& Korkie, (1981) tested the hypothesis using the treynor measures.

The third measure is Capital Asset Pricing Model (CAPM) that helps to calculate the investment risk and what return on the investment we should expect. Rizwan Qamar, Rehman, and Shah (2013)used the CAPM for the comparison of the portfolio performance among various companies in Pakistan. Jorion (1991) used the CAPM for measuring the expected returns of the active portfolio. A. Marathe \& Shawky (1994) used the CAPM for finding the Beta and concluded that time interval and frequency of evaluating stock return effects the beta.

The fourth measuring tool is the Jenson measure that calculates the excess return that a portfolio generates over its expected return. This measure is also known as Jenson Alpha. Naidenova, Parshakov, Zavertiaeva, and Tome (2015), applied the Jenson Alpha for 85 equity funds of Russian Economy.

The fifth measurement is the Diversification ratio, which is measured by volatility of portfolio as denominator and the summation of the product of each asset volatility with its weight.

Glancing at the 50 years back in a time machine, people knew nothing about the investment portfolios until 1960's there was nothing like fundamentals of investment portfolios. Shipway (2009) worked on the portfolio based on modern portfolio theory. As a matter of fact, before the advent of the portfolio theory people still had "portfolios" although their perception of portfolios building is totally different. In the year 1938, John Burr Williams wrote a book "The Theory of Investment value" discussing the "Dividend Discounted Model".

\subsection{Importance of the Problem}

This study explored the idea of simulated portfolio generation with the application of major investment strategies. Moreover, the strategies are further divided into various forms that provide a reflection into different dimensions of investment. Data is based on Pakistan stock market with three large sectors of KSE-100 index. This study provides an insight into the Pakistan stock and bond market as very little work is performed on generation of simulated portfolios containing both stocks and bonds. Moreover, the implementation of four investment strategies will provide a wide scale work on data.

\subsection{Literature Review}

Mattei and Mattei (2016)made an analysis on rebalancing strategies. The researcher worked on buy and hold strategy. The data employed consist of eight asset classes with 20 years returns. The methodology adopted for the comparison of risk-adjusted return of strategies includes the Return on investment, standard deviation and Sharpe ratio. The researchers concluded that if the investors find it difficult to rebalance the portfolio than there is a small difference between the risk adjusted return of buy and hold and rebalancing strategies.

Hilliard and Hilliard (2015) examined the buy and hold strategy using the portfolio of indices that were tracked through ETFs. The data collected was based on the monthly data ranged from 6-30-1992 until 10-31-2011. The researcher concluded that rebalancing the portfolio will beat the buy and hold strategy (no rebalancing) in all standard measures. This study is consistent with De Miguel et al. (2009) rebalancing strategies performed well than Markowitz strategy.

E. Hui, Yam, Wright, and Chan (2014)examined the buy and hold strategy for the real estate investment. The data of the six economies of Asia namely Hong Kong, China, Japan, Taiwan, Thailand and Malaysia has been analyzed. The data collected was based on securitized real estate indices bloom Berg for the period 10 July, 1995 to 31 December, 2012, seventeen years' times' series data total of 4561 observations. The researchers concluded that the trading strategy would outperform the buy and hold strategy, whether the transaction cost is present or not. 
Ling et al. (2014), studied the buy and hold strategy in relation to risk and return trade-off theory. The data is collected from indices of Malaysia, Singapore, Hong Kong and Korea for the period 1990-2009. The methodology adopted by researcher is the average rolling return of the Indexes and standard deviation for measuring the total risk. The researchers concluded that buy and hold strategy will reduce the equity risk and volatility of stock returns. However, the results fail to identify the enhancement in the stock return.

E. C. Hui and Yam (2014) investigated the Buy and hold strategy in contrast to trading strategy. Securitized real estate indices of four countries: US, UK, Canada and Germany were considered. The data of US: S\&P 500 Building Index, UK FTSE 350 Real Estate Index, Canada: S\&P/TSX Real Estate Index, Germany: construction PERF Index with the period of observation Januray2, 1990 to April 28, 2009 was used. Trading strategy was buildup to analyze the built up strategy on the four economies. The researcher concluded that buy and hold strategy underperforms than the trading strategy in case of low cost and vice versa.

Yam, Yung, and Zhou (2009) worked on the buying and hold strategy for buying the superior stock and sell the inferior stocks. . The selling of the stocks at the highest price over investment horizon are considered. The issue of selling and buying the stocks is catered by value of P-the probability of stock going up. The researchers found the three possible solution for buying and holding the stock based on the value of $\mathrm{P}$ relating to stock prices: first $\mathrm{P}$ is greater than $1 / 2$, selling the stock at the last time, secondly $p$ is equal to $1 / 2$, selling the stock at the maximum selling price, lastly if the value of $\mathrm{P}$ is less than $1 / 2$, at-once selling the stock is the best option.

Allaart and Monticino (2008) worked on Buy and Hold Strategy for commodities. Following the two trading strategies that falls into the two classes: first is buying and hold that was conservative and secondly the aggressive trading strategies that the continuous buy and selling of the commodities as the result of price variation. The data was collected from mutual funds based on 1000 companies-the Schwab 1000 index fund (SNFXF), from Dec 1, 2006 to Nov 30, 2007. The researchers found a lower variance in standard deviation in case of aggressive optimal strategies as compared to buy and hold strategies.

Shiryaev, Xu, and Zhou (2008) investigated buying and selling of the stocks over the given investment horizon. It is appealing to sell the stocks at the time when the price of the stock is maximum over the period of its horizon, which seems impossible over the overall investment horizon. The researchers provided the workable approach in which stocks are sold at price when expected relative error between the maximum price and selling price is minimum. They got the solution and used the methodology based on "goodness index" of stock, considering as the ratio of excess rate of return and volatility rate at maximum, was used to access the stock's quality. The researchers concluded, a stock is good for investor, mathematically termed as when alpha is greater than or equal to $1 / 2$.

Perold and Sharpe (1995b) have investigated the dynamic strategies for rebalancing and portfolio risk and return. The researcher analyses the hypothetical data ratio of $60 / 40$ in stocks/bonds for measuring the effectiveness of dynamic rebalancing strategies. The methodology employed was the investing in the stocks if the stock market falls and vice versa. The researchers concluded that the best strategy would be the one based on investor risk tolerance and based on investor's circumstances and desires.

Forsyth and Vetzal (2017)designed the dynamic strategy for asset allocation. The portfolio consisted of risk-free bond and an equity index. The data collected from CPI from US Bureau of statistics, the major US stock Exchange's monthly data on all the domestic stocks from the period 1926-2014. The researchers concluded that mean variance multi-period strategy would achieve the same expected terminal wealth goals as do the constant weight strategy.

Carroll, Conlon, Cotter, and Salvador (2017) investigated the dynamic correlation strategies between the assets for providing better performance as compared to equally weighted portfolio. The portfolios are generated of various sizes ranging from 9 international markets to 197 individual stocks. The methodology employed is variance co-variance matrix ad focusing on the correlation between assets. The results show that rebalancing will help in the best performance for the correlation based dynamic strategies.

$\mathrm{Li}$, Wei, and $\mathrm{Xu}$ (2017)explained the dynamic asset allocation and consumption pattern under the inflation. The researchers used the economic data of China specifically the inflation data of NBSC spanning from the third quarter of 2000 to the fourth quarter of 2011. The data showed that investors had differences in thoughts about inflation due to gap in the income, inequality in regions, measurement of inflation and differences in economic sector spending methods. The researchers concluded to provide the household investors with the channels for investing to cope with the inflation.

Chen, Ju, and Miao (2014) investigated the dynamic asset allocation in the scenarios of the predictability of ambiguous returns. The data collected from the US Stock Market over the time period of the 1927-2010 using the 
stock markets such as NASDAQ, NYSE and AMEX. The researchers concluded that there was the area in which the strategy of robustness allows the investors to have minimum stock allocation having the variables that were predictive.

Koijen, Rodriguez, and Sbuelz (2009)explored a model for the strategic asset allocation. The data collected ranging January 1946 to December 2005 based on the monthly data of the US in order to estimate the model. The researchers concluded that indices took 5 years to outperform myopic asset allocation and year cost is important than the investment horizon.

Liu, Longstaff, and Pan (2003) investigated the dynamic asset allocation. They considered the event risk that will bother a sudden change in price and risk of securities. An investor who feels and faces an event risk is not inclined towards taking the short position or leveraged one. The researchers concluded that optimal portfolios are affected by both the jumps in prices and volatility, whereas the investigation exercises of the researcher indicate that price jumps are more effective.

Brennan and Xia (2002) investigated about the dynamic asset allocation under inflation. Discussing the simplified form of framework analyzing the problem of the investor having finite horizon with inflation issues, in case when only nominal assets are available. The researcher concluded that whatever the stock-bond mix and bond maturity on optimal basis should focus and depend upon the horizon of investor and her risk aversion capability

Hoevenaars, Molenaar, Schotman, and Steenkamp (2008) investigated the Strategic asset allocation on the basis of liabilities. The methodology adopted by the researchers was the vector auto regression for liabilities, returns and the state-variables that were macro-economic in nature. The data collected started the time series form the 1952 to end in 2005 whereas the first observation for commodities start in 1970. The researchers concluded that the co-variance model is different for the stocks and bonds whereas the long term investors have different investment with value added asset classes.

Weigel (1991) described the performance of portfolio based on tactical asset allocation with risk and return. The data used was based on the17 US managers using the tactical asset allocation (TAA). The researcher concluded that the over sample period TAA managers shows more marketing skills. Furthermore, there was negative relationship between the market timing skills and investment abilities of a manager.

Jensen, Johnson, and Mercer (2002) investigated the tactical asset allocation for commodity futures relating to economic conditions. The monthly return data from January 1973 up to December 1999 of 12 different index. The measurement includes the Monthly returns, standard deviations and coefficient of variations. The researchers concluded that by adding futures commodities to the portfolio will enhance the portfolio return up to 100 basis points for average -risk portfolio.

Phillips and Lee (1989) explored about the tactical asset allocation by differentiating it with market timings. Being concerned about the short-term approach based on the market valuations, the strategic asset allocation approach is being tilted towards the tactical asset allocation that comprised of the said characteristics. Tactical asset allocation is differed with the market timers on the dimensions of time-frame, objectives, approach, and decision and performance measurement.

Dahlquist and Harvey (2001) examined the Global Tactical Asset Allocation. In their research they examined the three levels of strategies: the benchmark, the strategic and tactical asset allocation. The methodology employed is based on conditioning information of portfolio returns. The researchers concluded that returns are predictable means that active investment strategies outperform the passive investment strategies and uncovering the predictability is a challenging task as it will help the manager to beat the traditional benchmarks.

\subsection{Hypotheses and Their Correspondence to Research Design}

For analyzing the impact of Portfolio strategies on Portfolio risk and return. The following hypothesis are generated for testing the impact.

$\boldsymbol{H}_{\mathbf{0}}=$ Buy and Hold Strategy has positive impact on Portfolio risk and return.

$\boldsymbol{H}_{\mathbf{1}}=$ Buy and Hold Strategy has negative impact on Portfolio risk and return.

$\boldsymbol{H}_{0}=$ Dynamic Asset Allocation has positive impact on Portfolio risk and return.

$\boldsymbol{H}_{\mathbf{1}}=$ Dynamic Asset Allocation has negative impact on Portfolio risk and return.

$\boldsymbol{H}_{\mathbf{0}}=$ Strategic Asset Allocation has positive impact on Portfolio risk and return.

$\boldsymbol{H}_{\mathbf{1}}=$ Strategic Asset Allocation has negative impact on Portfolio risk and return. 
$\boldsymbol{H}_{0}=$ Tactical Asset Allocation has positive impact on Portfolio risk and return .

$\boldsymbol{H}_{\mathbf{1}}=$ Tactical Asset Allocation has negative impact on Portfolio risk and return.

The research design defined in this research study is based on generating the portfolios. The hypothesis will help in identifying the imoact of portfolio risk and return need of the investors.

\section{Method}

This study examines the impact of portfolio strategies on portfolio risk and return using different strategies and risk-adjusted returns ratios. The portfolio strategies are independent variable and portfolio risk and return are dependent variables. Three sectors of KSE 100 index with high market capitalization are considered that will generate a deep insight into investment portfolios and their impact on risk and return through simulated portfolios.

\subsection{Conceptual Framework}

Dependent variables are deducted from the independent variables. The portfolio allocation helps in defining the risk-adjusted returns. Perold and Sharpe (1995b) worked on Buy and hold and dynamic strategy by allocating 60/40 ratio. Mattei and Mattei (2016) also worked on buy and hold dynamic asset allocation.

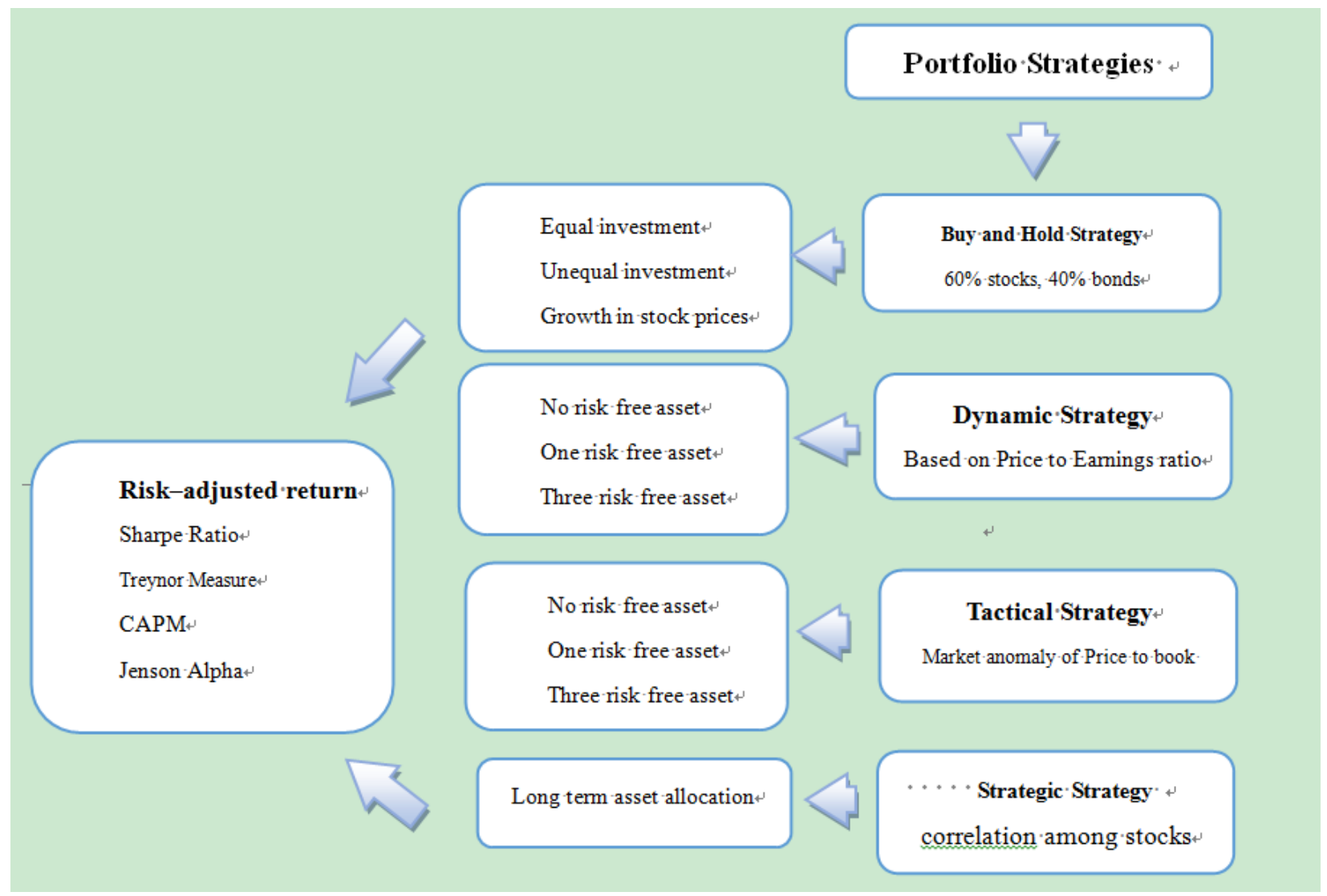

Source: developed by researchers

\subsection{Sampling Procedures}

In secondary research the sample size is defined in term of amount of data collected. The purposive sampling is applied from the non-probability sampling technique. The data has been collected month-wise for the period of 14 years. The No. of Observations (share prices) are 166 for annual portfolios and 1560 for the monthly portfolio from January, 2005 up to December, 2017. Data is based on KSE 100 Index, including the three sectors viz automobiles, Pharmaceutical and Cement for gauging the results, the top companies of KSE 100 index of three sectors have been included with highest market capitalization and outstanding shares. The market capitalization is KSE-100 index is 1924986.67 million. Sohail and Hussain (2011) inferred that macro-economic variables have positive effect on KSE-100 index in long run. Khan (2014) also inferred a positive relation among KSE 100 index and 
macro-economic variables

\subsubsection{Sample Size}

In this study, the small and medium cap companies due to low market capitalization only large cap companies has taken because of large market capitalization. For cement, automobiles and pharmaceutical firm's sample researcher has taken five companies with 14 years $(2005,2006,2007,2008,2009,2010,2011,2012,2013,2014,2014,2015$, 2016 \& 2017).

\subsubsection{Measures and Covariates}

The data is collected from various sources. The data is based on monthly share prices of the companies and monthly government bonds for portfolio generation. For this purpose, the major sources are the investment websites such as investing.com and company's annual reports. Companies' websites are also used for data gathering.

\subsubsection{Research Design}

Research design of this research is simulation based. Simulation represents the artificial representation of the real world phenomena. In this research the portfolios are generated according to the four portfolio strategies. Core and Guay (2002), analyzed the simulated stock option portfolios of the employees and their effect on price and volatility. Dietsch and Petey (2004) build the simulated portfolios for SME exposures in German and French market.

For the research two kinds of portfolio are generated, one on annual basis and other on monthly basis. These portfolios are further divided into 10 portfolios in each head. The portfolios are generated using excel software.

Using the simulation based techniques, 10 annual portfolios are generated under for main heads of strategies. The portfolios are generated using the monthly adjusted returns which are developed on the basis of share prices of the companies. The number of observation in these portfolios is 166 for 14 years' data. The variance-covariance matrices are developed on the basis of 14 years' geometric means and standard deviations. The variance-covariance matrix helps in generating the portfolio return, standard deviation and variance. The assets are allocated in the weights that help in calculating the return, standard deviation and variance. Beta of the market is calculated using the least square regression analysis. At the end these portfolios help in calculating the portfolio Sharpe ratio, Treynor measure, CAPM, Jenson Alpha and diversification ratio. These ratios help in analyzing the worth of portfolio strategies.

For generating the monthly portfolio, the risk-adjusted return and geometric mean of each month is calculated, along with the slope (Beta) of concerned month. The number of observation in these portfolios is 1560 for 14 years containing all the strategies month wise. The Sharpe ratio, Treynor measure, CAPM and Jenson Alpha is calculated for each month.

The data is collected from various sources. The data is based on monthly share prices of the companies and monthly government bonds for portfolio generation. For this purpose, the major sources are the investment websites such as investing.com and company's annual reports. Companies' websites are also used for data gathering.

\subsubsection{Experimental Manipulations or Interventions}

For the research two kinds of portfolio are generated, one on annual basis and other on monthly basis. These portfolios are further divided into 10 portfolios in each head. The portfolios are generated using excel software.

Using the simulation based techniques, 10 annual portfolios are generated under for main heads of strategies. The portfolios are generated using the monthly adjusted returns which are developed on the basis of share prices of the companies. The number of observation in these portfolios is 166 for 14 years' data. The variance-covariance matrices are developed on the basis of 14 years' geometric means and standard deviations. The variance-covariance matrix helps in generating the portfolio return, standard deviation and variance. The assets are allocated in the weights that help in calculating the return, standard deviation and variance. Beta of the market is calculated using the least square regression analysis. At the end these portfolios help in calculating the portfolio Sharpe ratio, Treynor measure, CAPM, Jenson Alpha and diversification ratio. These ratios help in analyzing the worth of portfolio strategies.

For generating the monthly portfolio, the risk-adjusted return and geometric mean of each month is calculated, along with the slope (Beta) of concerned month. The number of observation in these portfolios is 1560 for 14 years containing all the strategies month wise. The Sharpe ratio, Treynor measure, CAPM and Jenson Alpha is calculated for each month. At the end the non-parametric test is applied to check the worth of the portfolio strategies. 
Table 1. Asset allocation for portfolio simulations

\begin{tabular}{|c|c|c|c|}
\hline & Portfolio Strategies & Portfolios & Allocation \\
\hline \multirow[t]{3}{*}{1} & Buy and Hold (60/40) & With equal investments & $20 \%$ in each stock, $40 \%$ in bonds \\
\hline & & With unequal investments & $30 / 10 / 20$ in each stock, $40 \%$ in bonds \\
\hline & & With growth in stock prices & $\begin{array}{l}29 / 12 / 5 / 2 / 12 \text { in each stock, } 40 \% \text { in } \\
\text { bonds }\end{array}$ \\
\hline \multirow[t]{3}{*}{2} & Dynamic Asset Allocation & Without risk free asset & $100 \%$ in stocks \\
\hline & & With one risk free asset & $70 \%$ in stocks, $30 \%$ in bonds \\
\hline & & With three risk free assets & $55 \%$ in stocks, $45 \%$ in bonds \\
\hline \multirow[t]{3}{*}{3} & Tactical Asset Allocation & Without risk free asset & $100 \%$ in stocks \\
\hline & & With one risk free asset & $85 \%$ in stocks, $15 \%$ in bonds \\
\hline & & With three risk free assets & $70 \%$ in stocks, $30 \%$ in bonds \\
\hline 4 & Strategic Asset Allocation & With correlation among stocks & $45 \%$ in stocks, $55 \%$ in bonds \\
\hline
\end{tabular}

For empirical analysis One-way ANOVA along with Tukey's post hoc test is applied for comparing the means among groups. In this model, the difference between the four portfolio strategies along with their dimensions are taken as independent variables and four measures of risk and return are taken as dependent variables. For finding which portfolio strategies are different from each other, Tukey's post hoc test is applied. The model is defined by one way Anova equation in STATA.

$$
\text { One-way y Pid }
$$

Where y is risk- adjusted return measurements on individual basis and Pid are the portfolio strategies.

The theoretical form of the model is presented below:

One-way sharpe ratio portfolio strategies

One-way ANOVA helps in generation that portfolio strategies are different but it fails to tells which portfolio strategies are different from each other. For this purpose, Tukey's post hoc test is applied for knowing which strategies are statistically significantly different from each other. The mathematical formula for Tukey's post hoc test is:

$$
\mathrm{HSD}=\frac{\mathbf{M}_{\mathrm{i}}-\mathbf{M}_{\mathbf{j}}}{\sqrt{\frac{\mathbf{M S}_{\mathrm{w}}}{\mathbf{n}_{\mathrm{h}}}}}
$$

Where Mi-Mj = difference between the pair of means, Mi must be larger than $\mathrm{Mj} . \mathrm{MSw}=$ mean square within $\mathrm{N}=$ number of groups.

\section{Results}

Table 2 represents the specific results of the portfolio. Using the risk and return measures, ten annualized portfolios calculations are combined to analyze the measured results.

Using the risk adjusted measurements, the Sharpe ratio use the total risk of the investment. The higher the Sharpe ratio, the better the portfolio. The Buy and hold portfolio with equal and unequal investment has the highest Sharpe ratio of 0.0200 and 0.0100 respectively. The negative Sharpe ratio represents that risk free rate is greater than the portfolio mean return.

The Treynor measure uses the systematic risk of the investment. The systematic risk is measured by beta of the investment. The higher the treynor measure, the better the portfolio. The Buy and hold portfolio with equal and unequal investment has the highest treynor measure of 0.14 and 0.11 respectively. Treynor measure considers that portfolio is already diversified reasonably so, it does not consider unsystematic risk. The negative treynor measure means that risk free rate is greater than portfolio return.

The CAPM represents the Beta of the market for measuring the results of the portfolio. Measuring with CAPM, all portfolio except the three; buy and hold with growth in stock prices, dynamic asset allocation with one risk free asset and tactical asset allocation with one risk free asset will generate the minimum return of $0 \%, 1 \%$ and $4 \%$ respectively. All other portfolio's returns are better for investment. 
Alpha return is what investor looks for. Using the Jenson Alpha measurement, the portfolio generated with buy and hold strategy with growth in stock prices will generate an Alpha return of $4.70 \%$. Following with the Dynamic strategy with one risk free asset and tactical asset allocation with one risk free asset with Alpha return of $0.04 \%$ and $0.02 \%$ respectively. This shows that investor should consider minimum risk free asset for generating the Alpha return.

Table 2. Annualized portfolio measurements

\begin{tabular}{lllllll}
\hline \multicolumn{7}{c}{ Summarized Portfolio Measurements } \\
\hline Sr & Portfolio strategies & Portfolio & Sharpe & Treynor's & Jenson's & CAPM \\
& & SD & Ratio & Measure & Alpha & \\
$\mathbf{1}$ & Buy \& Hold (equal investment) & 0.1100 & 0.0200 & 0.0014 & -0.0010 & 0.0740 \\
$\mathbf{2}$ & Buy \& Hold (unequal investment) & 0.1300 & 0.0100 & 0.0011 & -0.0010 & 0.0800 \\
$\mathbf{3}$ & Buy \& Hold Growth in stock Prices & 0.0880 & -0.3300 & -0.0111 & 0.0470 & -0.0046 \\
$\mathbf{4}$ & Dynamic Strategy (no risk free asset ) & 0.6000 & 0.0004 & 0.0001 & -0.0004 & 0.0700 \\
$\mathbf{5}$ & Dynamic Strategy (one risk free asset ) & 0.4800 & -0.0500 & -0.0079 & 0.0004 & 0.0140 \\
$\mathbf{6}$ & Dynamic Strategy (three risk free asset ) & 0.3800 & -0.0400 & -0.0181 & -0.0030 & 0.0620 \\
$\mathbf{7}$ & Tactical Strategy (no risk free asset ) & 0.1800 & 0.0002 & 0.0001 & -0.0004 & 0.0700 \\
$\mathbf{8}$ & Tactical Strategy (one risk free asset ) & 0.3800 & -0.0300 & -0.0039 & 0.0002 & 0.0400 \\
$\mathbf{9}$ & Tactical Strategy (three risk free asset ) & 0.5400 & -0.0100 & -0.0091 & -0.0020 & 0.0700 \\
$\mathbf{1 0}$ & Strategic Asset Allocation & 0.3600 & -0.0400 & -0.0194 & -0.0040 & 0.0600 \\
\hline
\end{tabular}

\subsection{Empirical Analysis Results}

The ten monthly portfolios are generated using the four portfolio strategies. For examining the portfolios, the statistical tool of One-Way ANOVA along with Tukey's post hoc test is applied. The three measurements of risk-adjusted return; Sharpe ratio, Capital Asset pricing model and Jenson Alpha generates the significant results having $\mathrm{P}<0.05$, rejecting the null hypothesis of equal means, whereas the One Way ANOVA for treynor measure has insignificant result with $\mathrm{p}>0.05$, accepting the null hypothesis that of equal means among groups. Significant One-Way ANOVA realizes that strategies are different but Tukey's post hoc test is applied to know which strategies are different among others.

Results of One way ANOVA

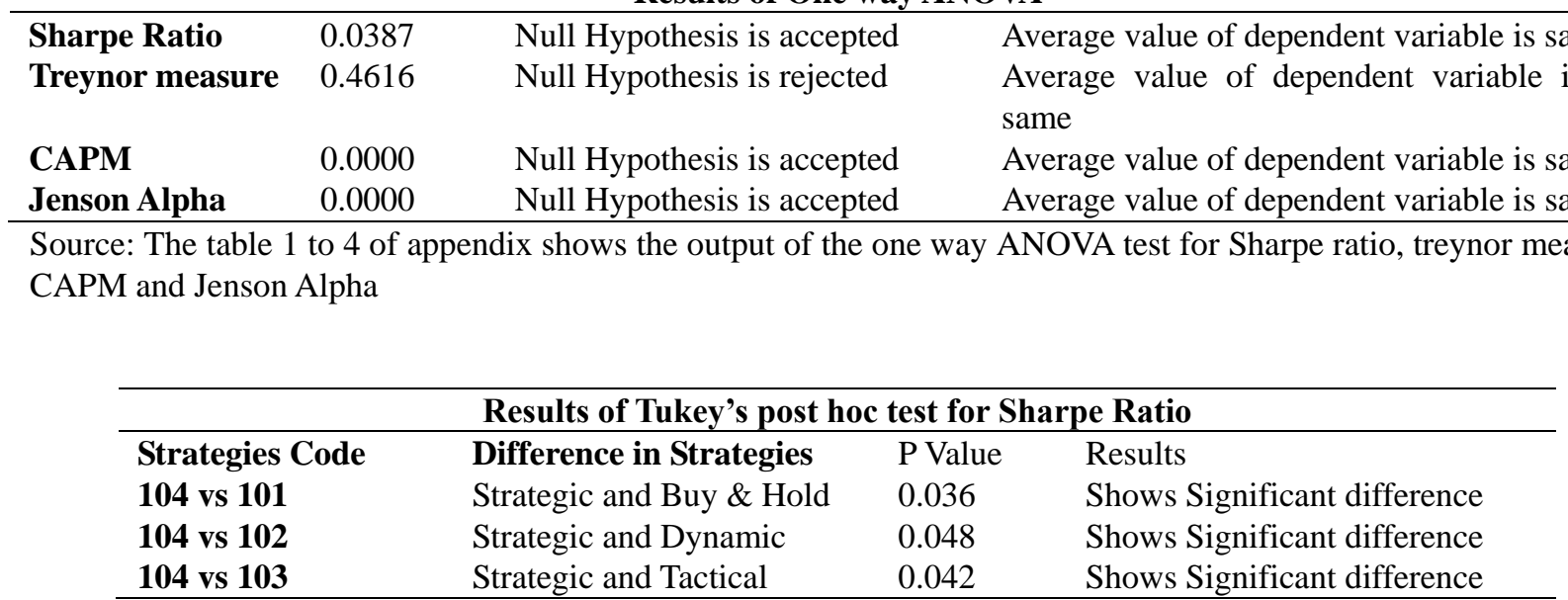

Source: The table 1 of appendix shows the output of the Tukey's posthoc test for Sharpe ratio

The Tukey's test for comparison of Portfolio Strategies on the basis of Sharpe Ratio(Y1) shows an average value difference between the strategic asset allocation (104) and Buy and Hold Strategy (101), the P-value is 0.036 which is less than 0.05. And between the Strategic asset allocation (104) and tactical asset allocation (103) having P-value is 0.042 


\begin{tabular}{llll}
\hline & \multicolumn{2}{c}{ Results of Tukey's post hoc test for Tryenor measure } \\
\hline Strategies Code & Difference in Strategies & P Value & Results \\
$\mathbf{1 0 4}$ vs 101 & Strategic and Buy \& Hold & 1.000 & Shows insignificant difference \\
$\mathbf{1 0 4}$ vs 102 & Strategic and Dynamic & 0.762 & Shows insignificant difference \\
$\mathbf{1 0 4}$ vs 103 & Strategic and Tactical & 0.805 & Shows insignificant difference \\
\hline
\end{tabular}

Source: The table 2 of appendix shows the output of the Tukey's posthoc test for Treynor measure.

The Tukey's test for Treynor measure doesnot show any significant difference between the groups as P-values of all the comparison groups are greater than 0.05. This signifies the insignificant result of One Way ANOVA for Treynor measure, that's shows that average value of no two groups are different from each other.As Jobson and Korkie (1981), shows that multivariate statistical test analysis for treynor measure does not produce a significant results.

\begin{tabular}{llll}
\hline & \multicolumn{3}{c}{ Results of Tukey's post hoc test for CAPM } \\
\hline Strategies Code & Difference in Strategies & P Value & Results \\
$\mathbf{1 0 4}$ vs 101 & Strategic and Buy \& Hold & 0.000 & Shows Significant difference \\
$\mathbf{1 0 4}$ vs 102 & Strategic and Dynamic & 0.000 & Shows Significant difference \\
$\mathbf{1 0 4}$ vs 103 & Strategic and Tactical & 0.000 & Shows Significant difference \\
\hline
\end{tabular}

Source: The table 3 of appendix shows the STATA output of the Tukey's posthoc test for CAPM.

The Tukey's test for comparison of Portfolio Strategies on the basis of CAPM (Y3) shows an average value difference between the strategic asset allocation (104) and Buy and Hold Strategy (101), the P- value is 0.000 which is less than 0.05. The difference between the strategic asset allocation (104) and Dynamic asset allocation (102), the $\mathrm{P}$-Value is 0.000 . And between the Strategic asset allocation (104) and tactical asset allocation (103) having P-value is 0.000 .

\begin{tabular}{llll}
\hline & \multicolumn{3}{c}{ Results of Tukey's post hoc test for CAPM } \\
\hline Strategies Code & Difference in Strategies & P Value & Results \\
$\mathbf{1 0 4}$ vs 101 & Strategic and Buy \& Hold & 0.000 & Shows Significant difference \\
$\mathbf{1 0 4}$ vs 102 & Strategic and Dynamic & 0.000 & Shows Significant difference \\
$\mathbf{1 0 4}$ vs 103 & Strategic and Tactical & 0.000 & Shows Significant difference \\
\hline
\end{tabular}

Source: The table 4 of appendix shows the output of the Tukey's posthoc test for Jenson Alpha

The Tukey's test for comparison of Portfolio Strategies on the basis of Jenson's Alpha (Y4) shows an average value difference between the strategic asset allocation (104) and Buy and Hold Strategy (101), the P- value is 0.000 which is less than 0.05. The difference between the strategic asset allocation (104) and Dynamic asset allocation (102), the P-Value is 0.000. And between the Strategic asset allocation (104) and tactical asset allocation (103) having P-value is 0.000 . The result is same as for treynor's measure.

\subsection{Difference in Strategies}

The risk adjusted return measurements reveals that strategic asset allocation based on correlation among stocks is statistically different from buy and hold strategy, dynamic asset allocation and tactical asset allocation in all their forms. Buy and hold strategy is passive but it focuses in those stocks that will generate the future profits.

\section{Discussion}

The basic goal of this study is to examine the impact of portfolio strategies on portfolio risk and return. The data is collected from the investing.com and company's annual reports from 2005-2017. The portfolio generated using this data is analyzed using variance co-variance matrix Excel and One-way ANOVA along with Tukey's post hoc test STATA.

On analyzing the ten annualized portfolios generated on the basis of four portfolio strategies. The Sharpe ratio and Treynor measure shows that buy and hold strategy with equal investment and buy generate a better risk-adjusted return with 0.020 and 0.140 respectively, whereas the Sharpe ratio and treynor measure with buy and hold strategy 
with unequal investment is 0.010 and 0.0011 respectively. If an investor wants to generate Alpha return, Buy and hold strategy with growth in stock prices portfolio will generate the Alpha return of $4.70 \%$. The dynamic asset allocation with one risk free asset and tactical asset allocation with one risk free asset generate $0.04 \%$ and $0.02 \%$ alpha returns.

The Statistical Analysis of the One-Way ANOVA and Tukey's Post hoc test produces the significant results that validates the null hypothesis that buy and hold, dynamic asset allocation, tactical asset allocation and strategic asset allocation have positive impact on the portfolio risk and return. The Tukey's Post hoc test proves that these strategies are different from each other and will impact the portfolio return and risk differently as the mean difference between their means is not equal to zero.

\section{Acknowledgements}

I would like to express my deepest gratitude to my venerable research mentor Sir Ahmad Shahzad, who provided the support to complete this reasearch. The support and appreciation of my family and colleagues is commendable during this journey, and they are highly appraised. I am also grateful to the worthy institute "The Lahore School of Accountancy and Finance, The University of Lahore" that provides me the opportunity to complete this research. I pay my honest gratitude to all my teachers for making and developing me what I am today. A special thanks is paid to Miss Abeera Shaukat (Mphil in English Literature) for her assistance in proof reading this research paper.

\section{References}

Allaart, P., \& Monticino, M. (2008). Optimal buy/sell rules for correlated random walks. Journal of Applied Probability, 45(1), 33-44. https://doi.org/10.1239/jap/1208358949

Anson, M.J. (2004). Strategic versus tactical asset allocation. The Journal of Portfolio Management, 30(2), 8-22. https://doi.org/10.3905/jpm.2004.319926

Brennan, M.J., \& Xia, Y. (2002). Dynamic asset allocation under inflation. The Journal of Finance, 57(3), 1201-1238. https://doi.org/10.1111/1540-6261.00459

Carroll, R., Conlon, T., Cotter, J., \& Salvador, E. (2017). Asset allocation with correlation: A composite trade-off. European Journal of Operational Research, 262(3), 1164-1180. https://doi.org/10.1016/j.ejor.2017.04.015

Chen, H., Ju, N., \& Miao, J. (2014). Dynamic asset allocation with ambiguous return predictability. Review of Economic Dynamics, 17(4), 799-823. https://doi.org/10.1016/j.red.2013.12.001

Core, J., \& Guay, W. (2002). Estimating the value of employee stock option portfolios and their sensitivities to price and volatility. Journal of Accounting research, 40(3), 613-630. https://doi.org/10.1111/1475-679X.00064

Dahlquist, M., \& Harvey, C. (2001). Global tactical asset allocation.

Dietsch, M., \& Petey, J. (2004). Should SME exposures be treated as retail or corporate exposures? A comparative analysis of default probabilities and asset correlations in French and German SMEs. Journal of Banking \& Finance, 28(4), 773-788. https://doi.org/10.1016/S0378-4266(03)00199-7

Forsyth, P.A., \& Vetzal, K.R. (2017). Dynamic mean variance asset allocation: Tests for robustness. International Journal of Financial Engineering, 4(02n03), 1750021. https://doi.org/10.1142/S2424786317500219

Hilliard, J.E., \& Hilliard, J. (2015). A Comparison of Rebalanced and Buy and Hold Portfolios: Does Monetary Policy Matter? Review of Pacific Basin Financial Markets and Policies, 18(01). https://doi.org/10.1142/S021909151550006X

Hoevenaars, R.P., Molenaar, R.D., Schotman, P.C., \& Steenkamp, T.B. (2008). Strategic asset allocation with liabilities: Beyond stocks and bonds. Journal of Economic Dynamics and Control, 32(9), 2939-2970. https://doi.org/10.1016/j.jedc.2007.11.003

Hui, E., Yam, P., Wright, J., \& Chan, K. (2014). Shall we buy and hold? Evidence from Asian real estate markets. Journal of Property Investment \& Finance, 32(2), 168-186. https://doi.org/10.1108/JPIF-09-2013-0059

Hui, E.C., \& Yam, S.C.P. (2014). Can we beat the "buy-and-hold" strategy? Analysis on European and American securitized real estate indices. International Journal of Strategic Property Management, 18(1), 28-37. https://doi.org/10.3846/1648715X.2013.862190

Jensen, G.R., Johnson, R.R., \& Mercer, J.M. (2002). Tactical asset allocation and commodity futures. The Journal of Portfolio Management, 28(4), 100-111. https://doi.org/10.3905/jpm.2002.319859 
Jobson, J.D., \& Korkie, B.M. (1981). Performance hypothesis testing with the Sharpe and Treynor measures. The Journal of Finance, 36(4), 889-908. https://doi.org/10.1111/j.1540-6261.1981.tb04891.x

Khan, M.S. (2014). Macroeconomic variables \& its impact on KSE-100 Index. Universal Journal of Accounting and Finance, 2(2), 33-39.

Koijen, R.S., Rodriguez, J.C., \& Sbuelz, A. (2009). Momentum and mean reversion in strategic asset allocation. Management Science, 55(7), 1199-1213. https://doi.org/10.1287/mnsc.1090.1006

Li, S., Wei, L., \& Xu, Z. (2017). Dynamic asset allocation and consumption under inflation inequality: The impacts of inflation experiences and expectations. Economic Modelling, 61, 113-125. https://doi.org/10.1016/j.econmod.2016.11.013

Ling, F.C.H., Yat, D.N.C., \& binti Muhamad, R. (2014). An Empirical Re-Investigation on the 'Buy-and-hold Strategy'in Four Asian Markets: A 20 Years' Study. World Applied Sciences Journal, 30, 226-237.

Liu, J., Longstaff, F.A., \& Pan, J. (2003). Dynamic asset allocation with event risk. The Journal of Finance, 58(1), 231-259. https://doi.org/10.1111/1540-6261.00523

Mattei, M.D., \& Mattei, N. (2016). Analysis of fixed and biased asset allocation rebalancing strategies. Managerial Finance, 42(1), 42-50. https://doi.org/10.1108/MF-10-2015-0264

Naidenova, I., Parshakov, P., Zavertiaeva, M., \& Tome, E. (2015). Look for people, not for alpha: mutual funds success and managers intellectual capital. Measuring Business Excellence, 19(4), 57-71. https://doi.org/10.1108/MBE-11-2014-0039

Perold, A.F., \& Sharpe, W.F. (1995a). Dynamic strategies for asset allocation. Financial Analysts Journal, 149-160. https://doi.org/10.2469/faj.v51.n1.1871

Perold, A.F., \& Sharpe, W.F. (1995b). Dynamic strategies for asset allocation. Financial Analysts Journal, 51(1), 149-160. https://doi.org/10.2469/faj.v51.n1.1871

Phillips, D., \& Lee, J. (1989). Differentiating tactical asset allocation from market timing. Financial Analysts Journal, 14-16.

Rizwan Qamar, M., Rehman, S., \& Shah, S. (2013). Applicability of Capital Assets Pricing Model (CAPM) on Pakistan Stock Markets. International Journal of Management and Business Research, 4(1), 1-9.

Sharpe, W.F. (1994). The sharpe ratio. Journal of Portfolio Management, 21(1), 49-58. https://doi.org/10.3905/jpm.1994.409501

Shipway, I. (2009). Modern portfolio theory. Trusts \& Trustees, 15(2), 66-71. https://doi.org/10.1093/tandt/ttn129

Shiryaev, A., Xu, Z., \& Zhou, X.Y. (2008). Thou shalt buy and hold. Quantitative Finance, 8(8), 765-776. https://doi.org/10.1080/14697680802563732

Sohail, N., \& Hussain, Z. (2011). The macroeconomic variables and stock returns in Pakistan: the case of KSE 100 Index. International Research Journal of Finance and Economics, 80, 66-74.

Weigel, E.J. (1991). The performance of tactical asset allocation. Financial Analysts Journal, 47(5), 63-70. https://doi.org/10.2469/faj.v47.n5.63

Yam, S., Yung, S., \& Zhou, W. (2009). Two rationales behind the 'buy-and-hold or sell-at-once'strategy. Journal of Applied Probability, 46(3), 651-668. https://doi.org/10.1239/jap/1253279844 


\section{Appendix}

Table 1. One-way ANOVA for sharpe ratio

. oneway yl pid

\begin{tabular}{crrrrr}
\multicolumn{5}{c}{ Analysis of Variance } & \\
Source & SS & df & MS & F & Prob > F \\
\hline $\begin{array}{l}\text { Between groups } \\
\text { Within groups }\end{array}$ & 157390.131 & 3 & 52463.3771 & 2.80 & 0.0387 \\
\hline Total & 29138827.3 & 1556 & 18726.7528 & & \\
Bartlett's test for equal variances: & chi2(3) $=91.8359$ & Prob>chi2 $=0.000$
\end{tabular}

Table 2. One-way ANOVA for treynor measure

. oneway y2 pid

\begin{tabular}{|c|c|c|c|c|c|}
\hline \multirow[b]{2}{*}{ Source } & \multicolumn{3}{|c|}{ Analysis of Variance } & \multirow[b]{2}{*}{$\mathrm{F}$} & \multirow[b]{2}{*}{ Prob $>\mathrm{F}$} \\
\hline & SS & df & MS & & \\
\hline Between groups & 8843.39073 & 3 & 2947.79691 & 0.86 & 0.461 \\
\hline Within groups & 5337772.15 & 1556 & 3430.44482 & & \\
\hline Total & 5346615.54 & 1559 & 3429.51606 & & \\
\hline
\end{tabular}

Table 3. One-way ANOVA for CAPM

\begin{tabular}{|c|c|c|c|c|c|}
\hline \multirow[b]{2}{*}{ Source } & \multicolumn{3}{|c|}{ Analysis of Variance } & \multirow[b]{2}{*}{ E } & \multirow[b]{2}{*}{ Prob > } \\
\hline & SS & $d f$ & MS & & \\
\hline Between groups & 667.692523 & 3 & 222.564174 & 12.57 & 0.0000 \\
\hline Within groups & 27555.663 & 1556 & 17.709295 & & \\
\hline Total & 28223.3555 & 1559 & 18.1034994 & & \\
\hline
\end{tabular}

Table 4. One-way ANOVA for jenson alpha

\begin{tabular}{|c|c|c|c|c|c|}
\hline \multirow[b]{2}{*}{ Source } & \multicolumn{3}{|c|}{ Analysis of Variance } & \multirow[b]{2}{*}{$\mathrm{F}$} & \multirow[b]{2}{*}{ Prob > $\mathrm{E}$} \\
\hline & SS & $d f$ & MS & & \\
\hline Between groups & 668.200452 & 3 & 222.733484 & 12.50 & 0.0000 \\
\hline Within groups & 27734.945 & 1556 & 17.8245148 & & \\
\hline Total & 28403.1454 & 1559 & 18.2188232 & & \\
\hline
\end{tabular}


Table 5. Tukey's post hoc test for sharpe ratio

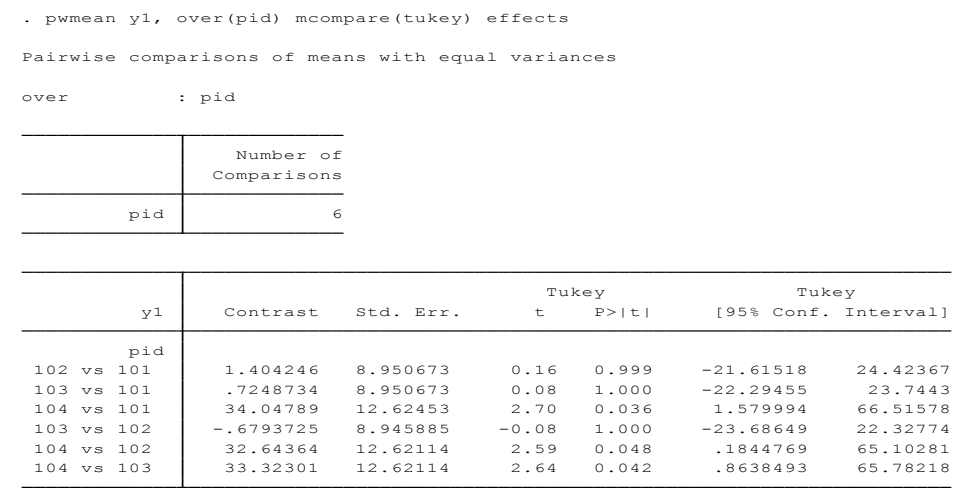

Table 6. Tukey's post hoc test for treynor measure

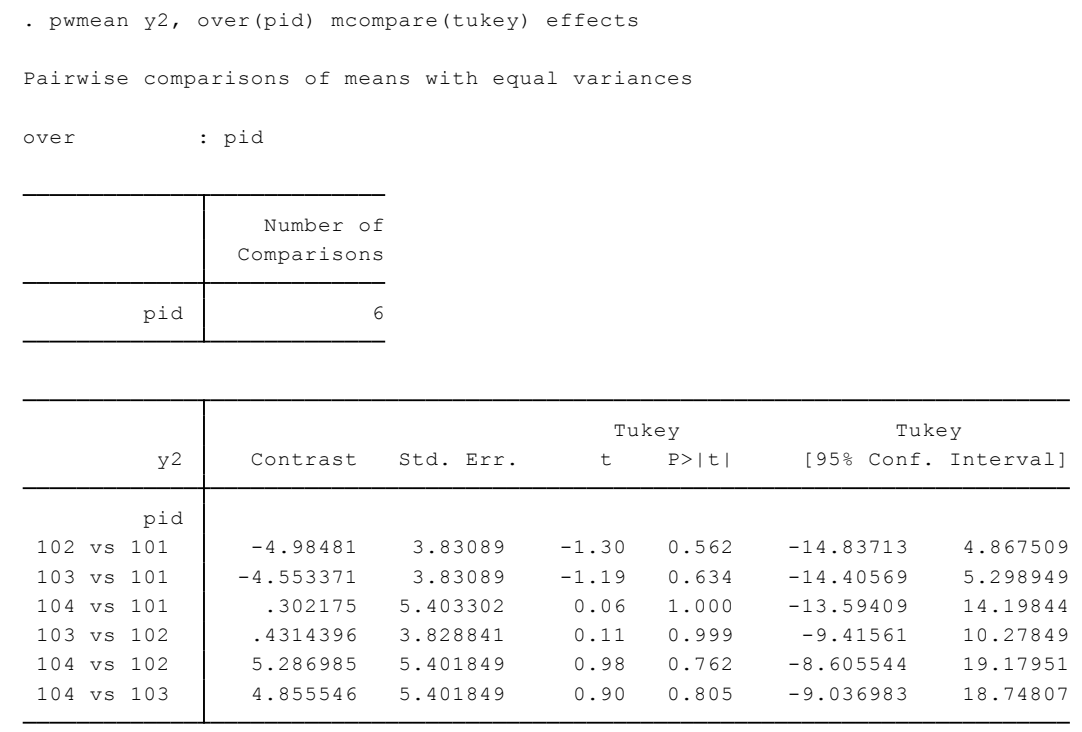

Table 7. Tukey's post hoc test for CAPM

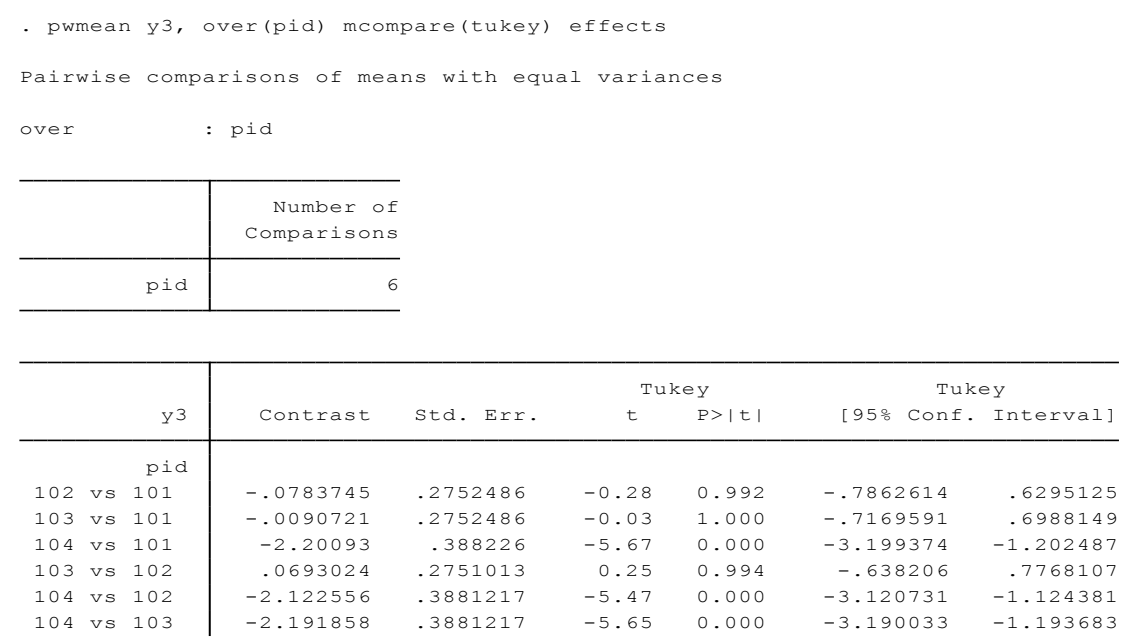


Table 8. Tukey's post hoc test for jenson alpha

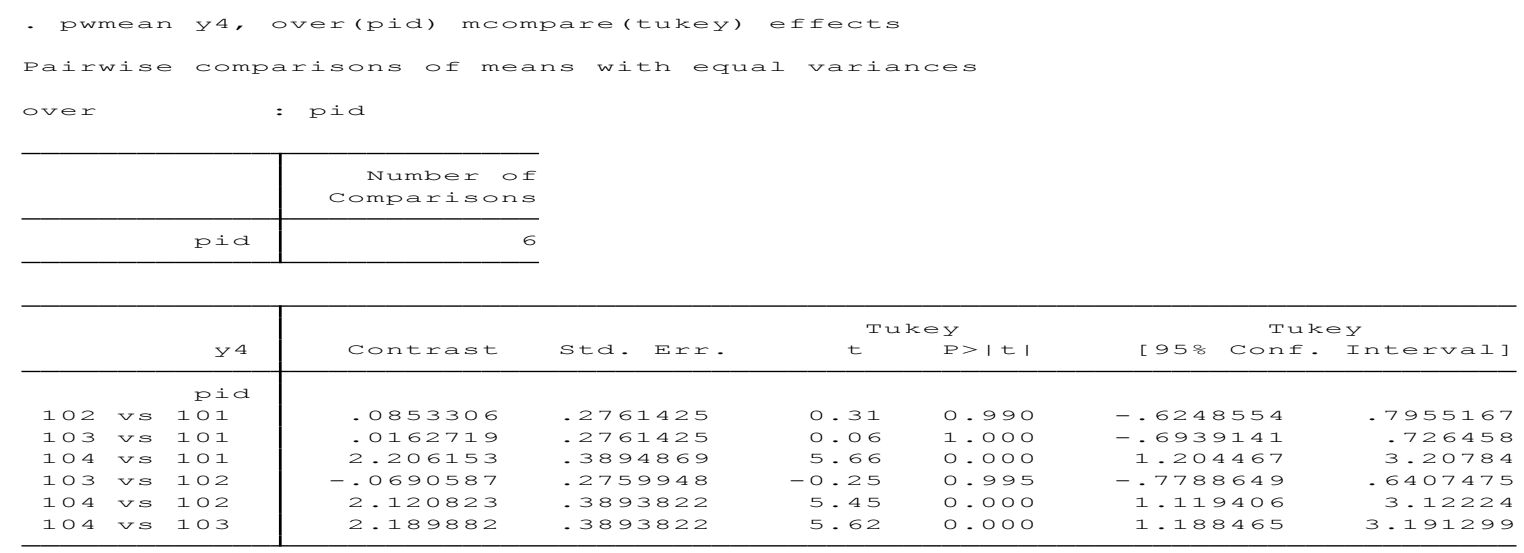

